\title{
periferio
}

\section{CONTORNOS DA EDUCAÇÃO FEMININA: A PROPOSTA EDUCATIVA DO EDUCANDÁRIO NOSSA SENHORA DA PIEDADE, 1925-1930}

\author{
Alexandre Neto ${ }^{1}$ \\ Universidade do Estado do Rio de Janeiro \\ Dayse Hora ${ }^{2}$ \\ Universidade Católica de Petrópolis
}

\section{Resumo}

Nosso texto intenciona abordar a proposta educativa do Educandário Nossa Senhora da Piedade em Paraíba do Sul, apresentando as especificidades da educação feminina expressa no currículo da instituição. Utilizamos como fonte documental de pesquisa o Testamento da condessa do Rio Novo. Esse documento é pouco usado em estudos no campo da Educação. Por meio dele conseguimos trazer à tona a criação da instituição escolar. Dialogaremos com os autores do campo do currículo, tais como: Zotti (2004), Moreira e Tadeu (2013) para discutir o currículo na Primeira República, corte temporal eleito por nós, nesse trabalho. Para compreender a questão de gênero são importantes as contribuiçõos de Perrot (2005), Del Priore (2007), Louro (2008) e Flexor (2009). No campo da História da Educação, os autores com os quais conversaremos são: Gondra e Schueler (2008) e por fim Hilsdorf (2007), para compreender a ação do Estado em favor da infância pobre.

Palavras-chave: educação feminina; currículo; educandário Nossa Senhora da Piedade; primeira república; Paraíba do Sul

\footnotetext{
${ }^{1}$ Possui doutorado em Educação pelo PROPED-UERJ. Mestre em História pela UNIRIO e graduado em História pela UERJ-FFP. Professor Adjunto do Programa de Pós-Graduação em Educação, Comunicação e Periferias Urbanas. Universidade Estadual do Estado do Rio de Janeiro. Faculdade de Educação da Baixada Fluminense. Coordenador do Núcleo de Pesquisa sobre Relações Étnico-raciais e Educação da UERJ-FEBF. História pela aleribeironeto@gmail.com

2 Doutora em Educação (Currículo) pela Pontifícia Universidade Católica de São Paulo (2000). É professora associada II, aposentada pela Universidade Federal do Estado do Rio de Janeiro (UNIRIO). Professora do Programa de Pós-Graduação em Educação. Universidade Católica de Petrópolis - UCP. dayse.hora@ucp.br
} 


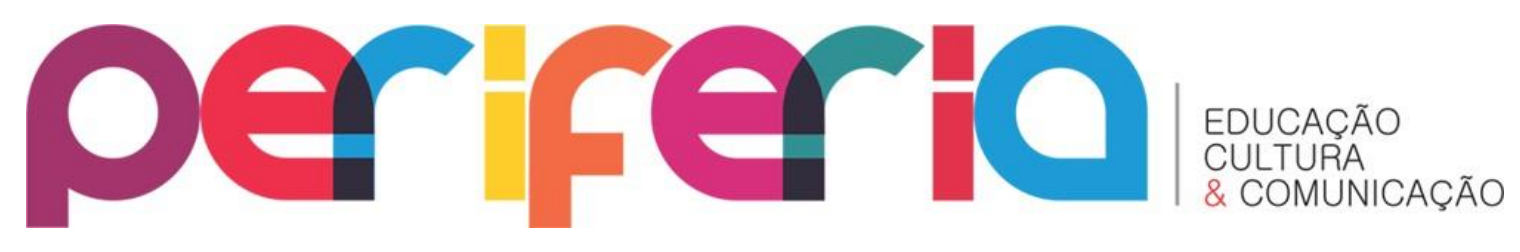

\section{PROFILES OF WOMEN'S EDUCATION: THE EDUCATIONAL PROPOSAL OF EDUCANDÁRIO NOSSA SENHORA DA PIEDADE, 1925-1930}

\section{Abstract}

Our text intends to talk about the educational proposal of Educandário Nossa Senhora da Piedade in Paraiba do Sul, presenting the specifics of female education expressed in the institution's curriculum. We used as a documentary source research Search the Testament of condessa do Rio Novo, this file little used in studies in the field of education. Through it, we can bring out the creation of the school. We will talk with the authors of the curriculum field, such as: Zotti (2004), Moreira e Tadeu (2013), to discuss the curriculum in the First Republic, temporal court elected by us in this work. In order to understand the gender issue, the Perrot (2005), Del Priore (2007), Louro (2008) and Flexor (2009). The field of History of Education: Gondra and Schueler (2008) and finally Hilsdorf (2007), to understand the action of the State in favor of poor children.

Keywords: female education; curriculum; educandário Nossa Senhora da Piedade, first republic; Paraíba do Sul 


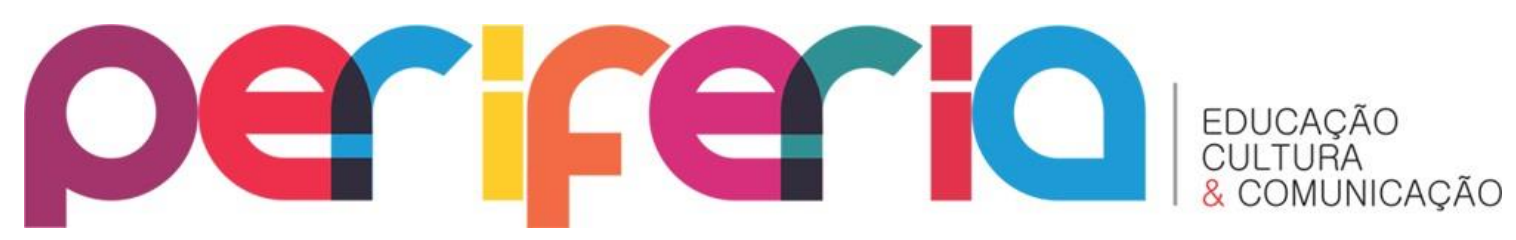

\section{INTRODUÇÃO}

0 presente texto toma como fio condutor a dissertação apresentada ao programa de Pós-graduação em Educação da UNIRIO - Universidade Federal do Estado do Rio de Janeiro, orientada pela $\mathrm{Pr}^{\mathrm{a}}{ }^{\mathrm{Dr}}$. ${ }^{\mathrm{a}}$ Ângela Maria Souza Martins em 2010. Depois da defesa, as alterações sugeridas foram feitas para a versão final do texto. Enquanto realizava a pesquisa documental do doutorado, o velho tema ainda me intrigava, de maneira que, nos intervalos de uma pesquisa me dedicava às investigações da antiga cuja temática foi a educação feminina em uma instituição escolar confessional católica. A dissertação tem prazo para terminar, agora sempre podemos voltar ao tema. Foi assim que nasceu o livro Tenha Piedade de Nós: uma análise da educação feminina do Educandário Nossa Senhora da Piedade, 1925-1930.

Nesse texto novas leituras foram feitas. Contudo, o principal fio dessa densa trama é o Testamento da condessa do Rio Novo. A instituição escolar foi criada a partir dele, para cumprir as vontades póstumas da gentil senhora. Em 1955 um grande incêndio destruiu a majestoso prédio e também o seu acervo documental. Para recompor o tecido social com lacunas e retirando as meninas pobres da sombra do anonimato, utilizamos como suporte teórico metodológico o Paradigma Indiciário, proposto por Ginzburg (1989), seguindo as pistas e indícios presentes na documentação. 0 objetivo do nosso estudo é compreender o Educandário Nossa Senhora da Piedade como contribuição de uma mulher da nobreza à educação de meninas pobres. Essa contribuição se fez com o auxílio da Igreja.

$\mathrm{O}$ texto é composto por três seções. Na primeira apresentamos a fundação do Educandário Nossa Senhora da Piedade em Paraíba do Sul, na segunda seção discutimos a relação existente entre gênero e educação de meninas pobres, na terceira abordamos a construção do currículo da instituição escolar. 


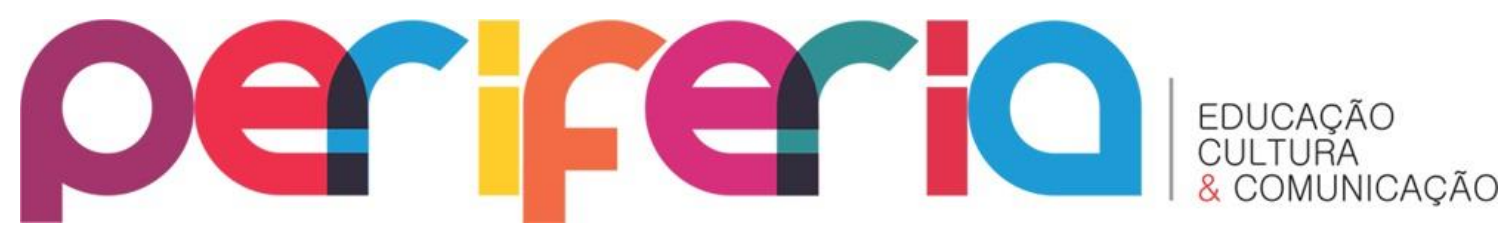

\section{A FUNDAÇÃO DO EDUCANDÁRIO NOSSA SENHORA DA PIEDADE EM PARAÍBA DO SUL}

A planta do edifício da Casa de Caridade de Paraíba do Sul, inaugurado no dia 8 de dezembro de 1882, foi desenhada pelo engenheiro e arquiteto Dr. Caminhoá e executada pelo engenheiro civil Francisco Rossi. Na parte mais alta da fachada, a condessa do Rio Novo mandou que fosse esculpida a figura de um pelicano simbolismo que significava para ela a preocupação com o bem geral, com o sofrimento das crianças pobres e órfãs, para os inválidos e doentes sem recursos. 0 primeiro Provedor foi Dr. Leandro Bezerra Monteiro. As irmãs de caridade chegaram ao asilo em 4 de abril de 1883. A primeira superiora foi a irmã Lúcia Guinhal (RIBEIRO NETO, 2010, p. 70).

O Educandário Nossa Senhora da Piedade foi fundando no ano de 1884 em Paraíba do Sul. Essa instituição era dirigida pela Irmandade Nossa Senhora da Piedade, e contava com o trabalho religioso e educacional da congregação São Vicente de Paula. Um belíssimo edifício no alto do morro de Santo Antônio, que chamava atenção pela grandiosidade e elegância o prédio de três andares possuía um pé direito alto, um grande número de janelas, que permitiam a ventilação e entrada da luz solar, marcava a paisagem da cidade acanhada, com ruas estreitas, com casas e sobrados coloniais.

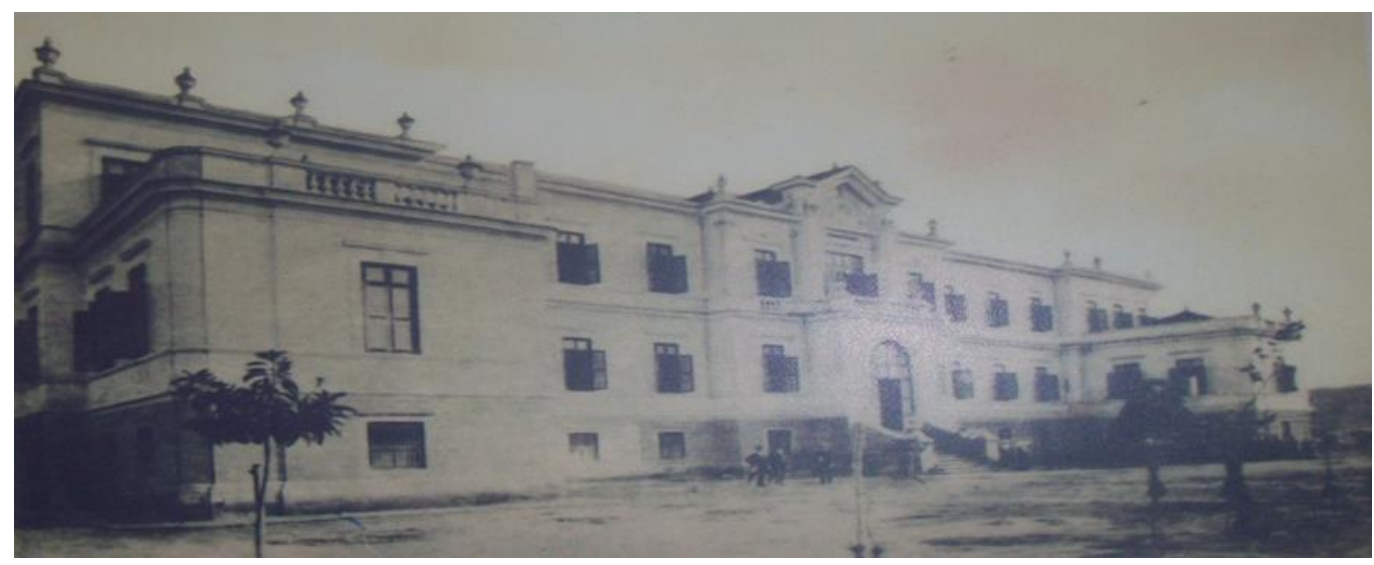

Fonte: Nicolino Visconti. Acervo do Centro Cultural Maria de Lourdes Tavares em Paraíba do Sul, s/d.

O Educandário foi construído com a verba testamentária de Mariana Claudina Pereira de Carvalho, condessa do Rio Novo, casada com seu primo o visconde do Rio Novo, sem herdeiros diretos. Flexor (2009) nos ajudar a 


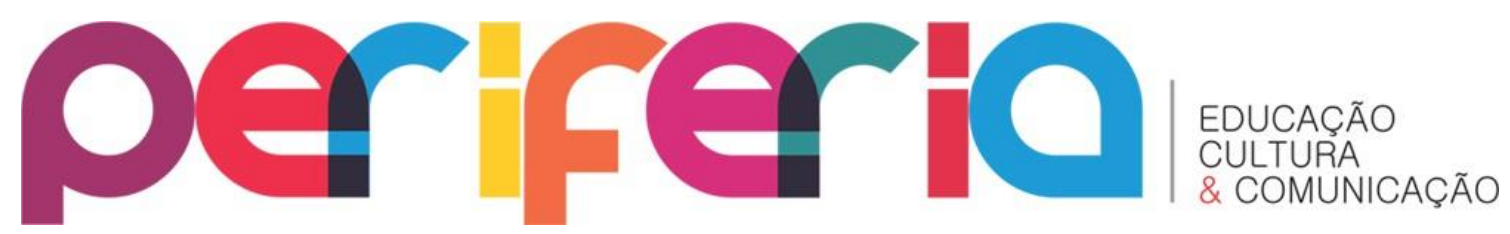

distinguir um inventário de um testamento, destacando a importância dos documentos judiciais para o estudo da História da Educação.

É importante salientar que, nem sempre os inventários e os testamentos constituíam um único processo ou eram indissociáveis. Os inventários eram feitos quando existiam órfãos menores e bens a serem partilhados e podiam ou não incluir testamento [...]. 0 testamento era facultativo, o inventário obrigatório quando houvesse bens (FLEXOR, 2009, p. 25).

Os prédios mais imponentes construídos no mesmo período são o Palacete Ribeiro de Sá, casa do Barão Ribeiro de Sá, o Fórum e a Câmara Municipal. A Capela de Nossa Senhora das Graças, em estilo neogótico, que completa o conjunto de prédios históricos foi construída depois em 1923.

Eles são testemunhas de um tempo de glória e riqueza do café, produto que junto com o gado leiteiro e a lavoura trouxe para a cidade alguns imigrantes italianos e portugueses. Não podemos esquecer dos viajantes que subiam a serra, pelos trilhos da Ferrovia Central do Brasil e D. Pedro II. Desde os tempos coloniais a cidade beneficiava-se da proximidade com Minas Gerais, constituindo-se importante entreposto comercial para os que almejavam alcançar o Rio de Janeiro.

A escola-edifício é marcada por micro poderes, que disputam a implementação de projetos, cujo raio de ação vai desde a elaboração de currículos, da carga horária das disciplinas, do número de alunos em sala, do material didático escolhido, até a arquitetura dos prédios escolares, que carregadas de subjetividade são sinais, que nos permitem compreender as sociedades que os construíram.

Como a escola-edifício deve ser um operador de adestramento. Fora uma máquina pedagógica que Paris-Duverney concebera na Escola militar e até nos mínimos detalhes que lhe impusera a Gabriel. Adestrar corpos vigorosos, imperativo de saúde, obter oficiais competentes, imperativo de qualificação; formar militares obedientes, imperativo político; prevenir a devassidão e a homossexualidade, imperativo de moralidade. Quádrupla razão para estabelecer separações estanques entre os indivíduos, mas também aberturas para a observação contínua. 


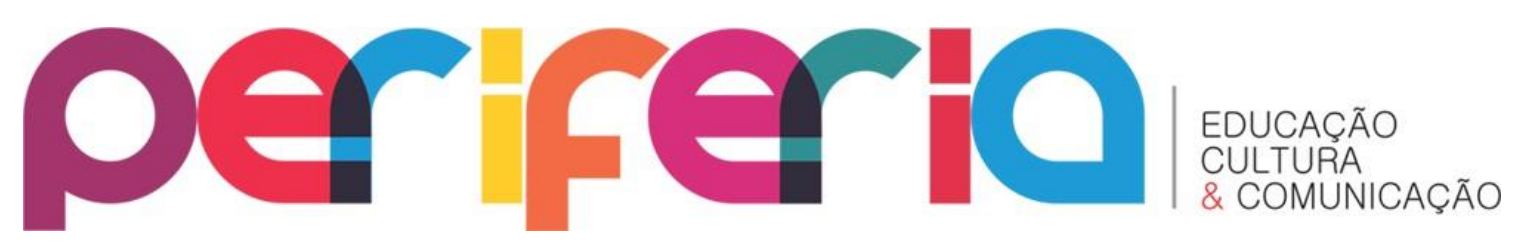

O próprio edifício da Escola deveria ser um aparelho de vigiar (FOUCAULT,1998, p.80).

O edifício do Educandário Nossa Senhora da Piedade foi erguido dentro do imperativo da moralidade, para evitar a devassidão das meninas desvalidas. Foucault apresenta o edifício escolar como integrante do aparelho de vigia, a sua forma arquitetônica, pensada para estabelecer a separação dos indivíduos, podia também ser lida como uma tentativa de separar o espaço público do privado, a casa da escola. Se as janelas foram pensadas como entradas de ar e luminosidade elas também possibilitavam a vigilância.

As terras deixadas pela condessa do Rio Novo formavam a fazenda Cantagalo, que foi doada aos escravos que ela libertou. Uma parte da produção agrícola deveria ser doada, para ajudar no sustento do Educandário Nossa Senhora da Piedade. Entre as vontades póstumas da gentil senhora encontravase também o desejo de construir um hospital. Seus bens foram administrados pela Irmandade Nossa Senhora da Piedade, que procurou cumprir as cláusulas do testamento.

Entretanto, uma pergunta ainda não foi respondida, quem era o Dr. Caminhoá que projetou o prédio? 0 belíssimo prédio do Educandário Nossa Senhora da Piedade pegou fogo em 1955, juntamente com ele parte de seu acervo. No material que coletamos nessa instituição, reinava o absoluto silêncio sobre a presença do ilustre engenheiro e arquiteto em Paraíba do Sul. A saída encontrada foi procurar informações sobre ele, em outra instituição de pesquisa. Fomos buscar a resposta para a pergunta, nos acervos da Biblioteca Nacional.

No acervo da Biblioteca Nacional consultamos os dicionários biobliográficos Sacramento Blake e Velho Sobrinho, para descobrir alguma informação sobre o engenheiro e arquiteto Dr. Caminhoá, que desenhou o prédio. Descobrimos a existência de três irmãos: Francisco de Azevedo Monteiro Caminhoá, Joaquim Monteiro Caminhoá, Luiz Antônio Monteiro Caminhoá. Filhos de Manoel José Caminhoá e de dona Luiza Monteiro Caminhoá. Da lista de possibilidades devemos excluir Joaquim, o segundo filho do casal, pois ele 


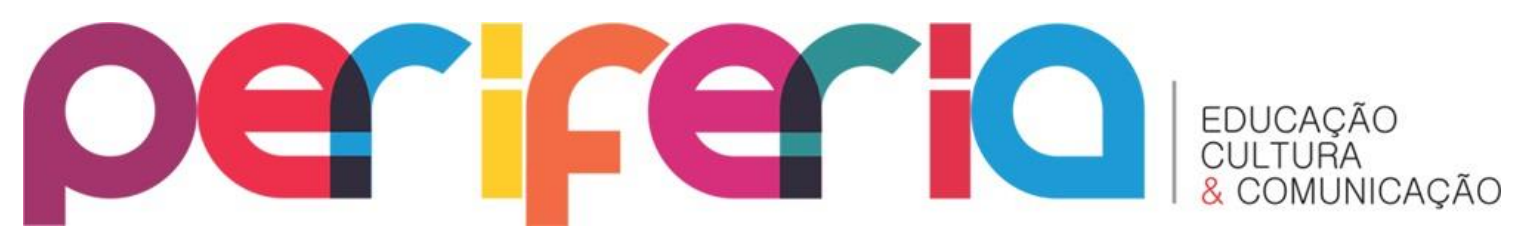

era formado em Medicina. Tanto Francisco como seu irmão caçula, Luiz Antônio eram formados em engenharia. Qual dos dois teria projetado o prédio?

O dicionário biobliográfico Sacramento Blake nos fornece poucas informações sobre Francisco, isso talvez tenha ocorrido devido a sua modesta atuação política. 0 verbete sobre ele, não menciona nem mesmo o ano do nascimento e morte.

Francisco de Azevedo Monteiro Caminhoá - Filho de Manoel José Caminhoá e de dona Luiza Monteiro Caminhoá. Natural da cidade da Bahia, e engenheiro civil, formando em Paris. Escreveu: Documentos, juízo crítico e orçamento relativo ao monumento patriótico do Brasil, destinado ao Campo da Aclamação no Rio de Janeiro; publicados por ordem da ilustríssima Câmara municipal da corte do Rio de Janeiro (BLAKE, 1899, p. 405).

Luiz Antônio Monteiro Caminhoá teve atuação política mais destacada. Nasceu na Bahia em 1842, o que nos ajuda a pensar a origem da sua família. Não sabemos se toda família mudou para o Rio de Janeiro. Contudo, ele faleceu em 1886, aos quarenta e quatro anos de idade na corte. Assentou praça como Alferes na Guerra do Paraguai, foi cavalheiro da Ordem de Cristo. Sua formação como engenheiro se deu na Europa, dedicando-se à área agrícola. Escreveu livros, participou da exposição agrícola de Viena em 1874. Quando dela regressou foi nomeado diretor da Escola Agrícola de Juiz de Fora. Criou nessa instituição o Museu Agrícola e o Gabinete de Mineralogia e de Anatomia Comparada.

Além de buscar dados nos acervos das instituições de memória, dialogamos também com a bibliografia existente. Alessandra Frota Martinez em sua dissertação de mestrado em História, ao analisar a atuação da Associação Protetora da Infância Desamparada, nos ajudou a descobrir qual dos dois irmãos, teria projetado o prédio do Educandário Nossa Senhora da Piedade em Paraíba do Sul. Ao apresentar o grupo de homens que fundou a associação citada acima, entre eles, ela menciona o nome de Luiz Monteiro Caminhoá. 


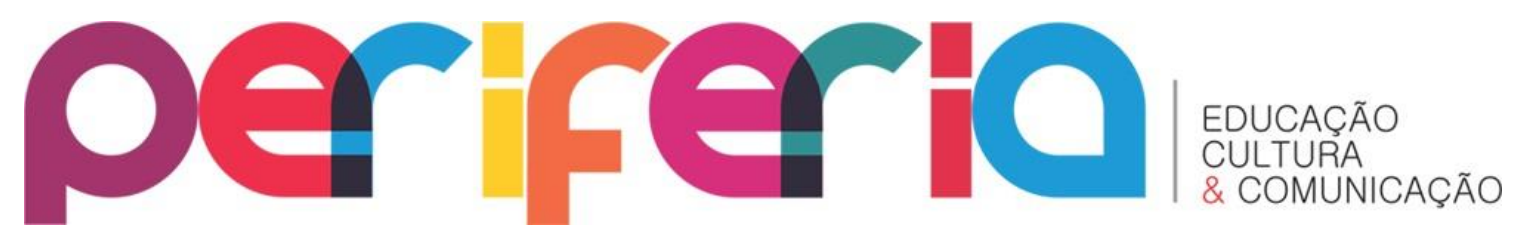

Em 29 de Julho de 1883, um grupo de homens públicos resolveu colocar a proposta em prática. Ilustres dirigentes imperiais reuniram-se para fundar a Associação Brasileira Protetora da Infância Desamparada. Presidindo a iniciativa, o Sr. Gastão de Orleans e Bragança, o Conde D'Eu. Juntamente com o genro do imperador, encontravam-se na Diretoria: o Visconde de Bom Retiro (Luiz Pedreira do Couto Ferraz), autor do primeiro Regulamento de Instrução Primária e Secundária da Corte; os Conselheiros Manoel Francisco Correia e Carlos e Leôncio de Carvalho; Henrique de Beaurepaire-Rohan; Nicolau Joaquim Moreira; o Deputado Francklin Américo de Menezes Dória e Luiz Monteiro Caminhoá (MARTINEZ, 1997, p. 186).

Luiz Monteiro Caminhoá no ano de 1883, contava com quarenta e um anos de idade. Já havia retornado de sua viagem a Exposição Agrícola de Viena, e ocupava também o cargo de diretor da Escola Agrícola de Juiz de Fora. Seus conhecimentos em estabelecimentos de ensino agrícola, o levaram a Paraíba do Sul, em busca de terras para instalação de uma colônia agrícola.

Os primeiros passos para a busca de terreno foram dados pelos senhores Luiz Antônio Caminhoá e Paulino José Soares de Souza. Influentes nas regiões do Vale do Paraíba fluminense procuravam auxílio junto à Irmandade Nossa Senhora da Piedade, solicitando que fossem cedidos à Associação Protetora parcelas do patrimônio deixado como herança pela Condessa do Rio Novo, antiga proprietária da Fazenda Cantagallo, em Paraíba do Sul. Após permissão dos "irmãos", uma Comissão de associados procedeu a visitas e inspeções dos terrenos. No entanto, os pareceres sobre o local não foram favoráveis, já que as terras não eram apropriadas ao "cultivo de cana-deaçúcar, do café e outras plantas” (MARTINEZ, 1997, p. 190).

Luiz Antônio Caminhoá provavelmente sabia da existência do vasto legado deixado pela gentil senhora, viúva, sem herdeiros naturais. Quando a Associação Protetora da Infância Desamparada buscou um lugar para construir uma instituição, Luiz Antônio Caminhoá voltou à cidade e consultou os membros da Irmandade, sobre a possibilidade de doação de terras.

Mariana Pereira Claudina de Carvalho, a condessa do Rio Novo morreu em 1882. Quando a associação foi fundada seu testamento provavelmente já havia sido lido, e os esforços para cumpri-lo também. No ano de 1883 o prédio já estava pronto e recebeu as primeiras irmãs vicentinas, o que nos permite 


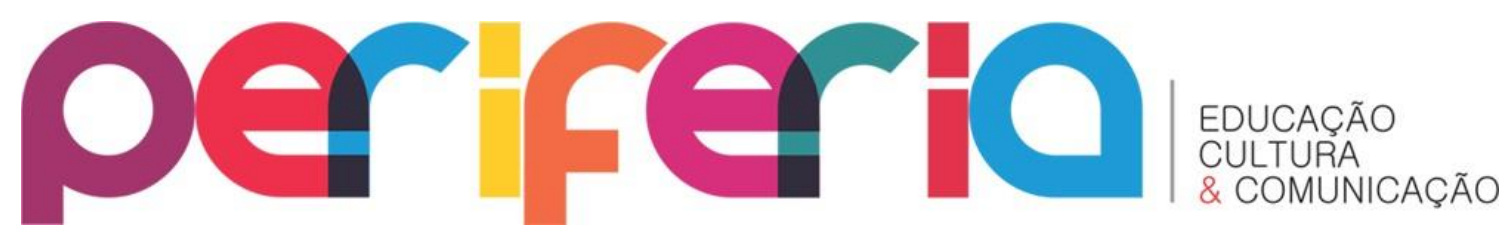

pensar que Luiz Antônio Monteiro Caminhoá esteve antes em Paraíba do Sul, projetando o edifício, e soube das terras deixadas por ela, para o sustento do Educandário Nossa Senhora da Piedade. Contudo, as terras da fazenda do Cantagalo já apresentavam um alto grau de envelhecimento, devido ao plantio de café na região, o que impossibilitava a construção de um Asilo Agrícola.

O local escolhido para a construção do asilo agrícola foi à propriedade doada pela baronesa de Santa Mônica e seu filho Nicolau de Lima Nogueira da Gama. Segundo os pareceres, o mesmo reunia as condições necessárias para a prática da agricultura. Ouçamos a historiadora mais uma vez:

Apenas em 1886, após quase quatro anos da fundação da iniciativa, que os impasses da localização da instituição foram solucionados. A Baronesa de Santa Mônica e seu filho Francisco Nicolau de Lima Nogueira da Gama, ofereceram a "Chácara Monte Scylenne" situada a um quilômetro da Estação do Desengano, próximo à Valença. O negócio foi fechado e o Asilo Agrícola de Santa Isabel foi inaugurado em 28 de abril de 1886, na comemoração do natalício do Conde D'Eu (MARTINEZ, 1997, p. 190).

A cidade de Paraíba do Sul não recebeu apenas a visita do ilustríssimo engenheiro. Ela recebeu também, a visita de Gastão de Orleans e Bragança, o Conde D'Eu, que se impressionou com a grandiosidade das obras de caridade realizadas, em favor da infância desamparada. Encontramos a notícia da visita do nobre, no jornal $O$ Vassourense, publicado em Vassouras.

Aqui esteve no dia 18, Sua Alteza Real o Senhor Conde D 'Eu. Depois de almoçar em casa do senhor Barão da Cananéia visitou os edifícios públicos, e seguiu para a fazenda do senhor Doutor Lazzarini, onde jantou e pernoitou. A Câmara municipal que sabia oficialmente da vinda de Sua Alteza, pois que vinha expressamente ver a casa do Asilo Furquim, esqueceu-se de que tinha o dever, ao menos de delicadeza, de convidar as autoridades públicas para receber Sua Alteza. Não admira que tenha cometido essa falta, quem não faz outra coisa, senão cometer faltas como a atual municipalidade, desde que está de posse das cadeiras edis. Apesar desse esquecimento as autoridades compareceram espontaneamente, a tornar mais solene a recepção do ilustre hóspede. Sua Alteza ao visitar o Asilo Furquim deveria admirar-se ao saber que há 4 anos que a casa foi doada, e que a municipalidade nada tem feito para se 


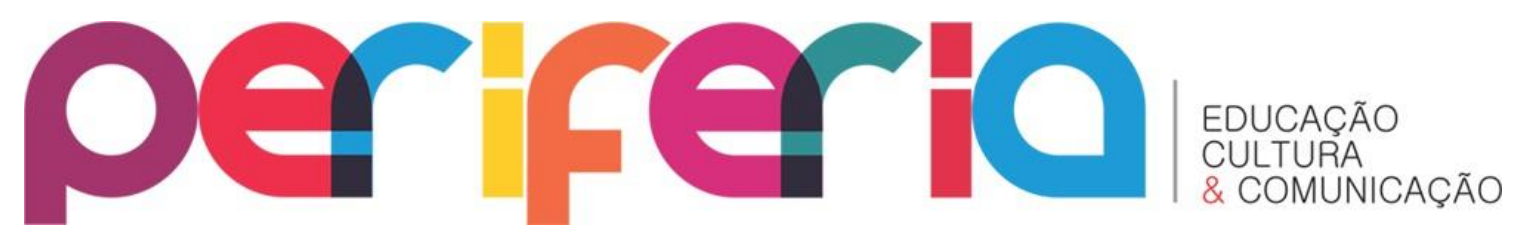

levar realidade a ideia do Doutor Furquim, limitando-se apenas a nomear umas comissões, que compreenderam bem a inércia municipal, não dando apreço às suas nomeações, nem tratando de agenciar donativos, fim para que forão criadas. Consta-nos que Sua Alteza não se retirou muito satisfeita da Câmara municipal. Na verdade, depois de visitar a da Paraíba do Sul, que tanto tem pugnado pelos interesses do seu município, a vista a daqui, que nada faz devia ser muito desagradável ( 0 VASSOURENSE, 1884, p.1).

Tomando como base o ano da publicação do jornal, o Conde D'Eu visitou a cidade de Paraíba do Sul, no ano da inauguração do Educandário Nossa Senhora da Piedade. Provavelmente foi recebido pela Câmara municipal e autoridades locais, com todas as deferências que a ocasião pedia. Sua vontade de combater o analfabetismo, promovendo a escolarização dos desamparados, o fez saudar a iniciativa dos comerciantes, homens públicos e membros da nobreza, que promovendo a Instrução Pública auxiliavam o Império a combater a sua maior doença: o analfabetismo.

O periódico parabeniza a cidade de Paraíba do Sul, pois em Vassouras o quadro não era o mesmo, as obras do Asilo Furquim encontravam-se atrasadas. O Educandário Nossa Senhora da Piedade, por seu próprio nome, evidência uma proposta católica de educação. O Educandário Nossa Senhora da Piedade atuava em duas frentes: uma era a educação das meninas, o que devido ao pequeno número de escolas públicas, denunciava a dificuldade das mesmas em se matricular numa escola regular. A outra frente de atuação era o cuidado preventivo para livrá-las da prostituição incutindo nelas os ensinamentos católicos. 0 prédio estava pronto. 0 que ensinar às meninas?

\section{A CONTRIBUIÇÃO DE UMA MULHER DA NOBREZA À EDUCAÇÃO DE MENINAS POBRES}

Os estudos sobre a educação das mulheres da nobreza ganharam um novo folego. Não é objetivo central desse texto. Todavia não podemos negar a importância desses estudos para a História da Educação. No campo da História, um dos primeiros estudos realizados nessa área no Brasil foi realizado pela professora Rachel Soihet em sua dissertação de mestrado, defendida no Programa de Pós-graduação em História da UFF, no ano de 1974 já indicando a trilha que a pesquisadora seguiria. Em, 1986, em sua tese de doutorado a pesquisadora debruçou-se novamente sobre o tema, discutindo Periferia, v. 10, n. 2, p.158-180, jul./dez. 2018 


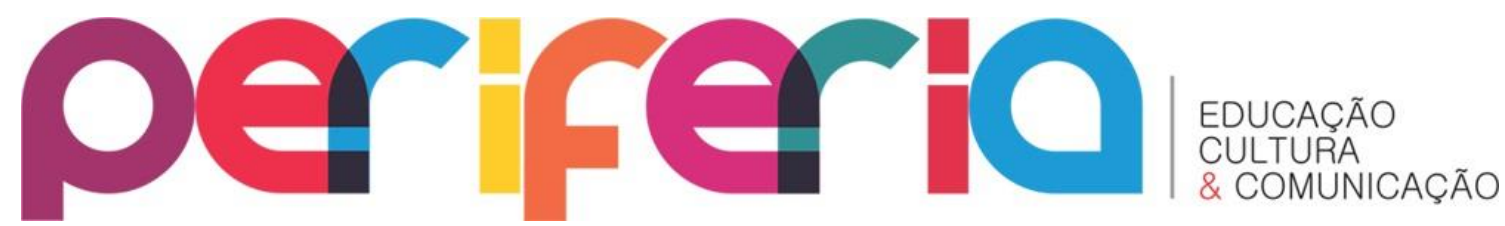

Vivências e Formas de Violência: Mulher de Classe Subalterna no Rio de Janeiro (1890

- 1920). Rachel Soihet possui muitos artigos sobre essa temática, gostaríamos de indicar o capítulo intitulado História das Mulheres, publicado no livro Domínios da História, organizados pelos professores Ronaldo Vainfas e Ciro F. Cardoso. Fora do Brasil, os estudos sobre a História das mulheres apresentam uma vasta produção. Contudo, gostaríamos de indicar duas pesquisadoras que contribuíram muito nesse debate. São elas: Michele Perrot ${ }^{3}$ e Natalie Zemon Davis ${ }^{4}$.

Em 2007, Mary Del Priore organizou uma coletânea importante sobre o tema e nele encontramos artigos de diferenças, pesquisadoras, que sob diferentes perspectivas analisam a História das Mulheres. Jaqueline Aguiar e Maria Celi Vasconcelos, em 2012 publicaram um artigo sobre a educação das princesas Isabel e Leopoldina e atualmente seguem suas pesquisas sobre mulheres da nobreza. Em 2013, Mary Del Piore voltou ao tema no livro Castelos de papel, no qual apresenta o processo de escolarização das princesas Isabel e Leopoldina. Sobre a educação de mulheres da nobreza, temos o importante estudo de Mariana de Muaze - As memórias da viscondessa: família e poder no Brasil Império. Nesse livro a autora através da correspondência trocada entre os membros da família Velho de Avellar apresenta a participação das mulheres na administração do patrimônio familiar.

Louro (2008) nos apresenta o conceito de gênero como produto das relações sociais:

Pretende-se, dessa forma recolocar o debate no campo do social, pois é nele que se constroem e se reproduzem as relações (desiguais) entre os sujeitos. As justificativas para as desigualdades precisariam ser buscadas não nas diferenças biológicas (se é que mesmo essas podem ser compreendidas fora de sua constituição social), mas sim nos arranjos sociais, na história, nas condições de acesso aos recursos da sociedade, nas formas de representação (LOURO, 2008, p.22).

\footnotetext{
${ }^{3}$ Alguns que se interessam pelo tema. Indicamos. A mulheres ou o silêncio da História. Publicado no Brasil pela EDUSC em 2005, pela pesquisadora Michelle Perrot. Da mesma autora outra obra que merece destaque é Minha História das Mulheres, publicado pela editora Contexto em 2007.

${ }^{4}$ Natalie Zemon Davis possui uma vasta produção de livros, artigos, capítulos de livros que são importantes para os estudiosos da temática. Contudo, indicamos dois livros que podem contribuir para quem está escrevendo sobre o tema. São eles: Nas margens: Três mulheres do século XVII, publicado em 1997e História de perdão: e seus narradores na França do Século XVI, publicado em 2001. Os dois livros foram lançados no Brasil pela Companhia das Letras.
} 


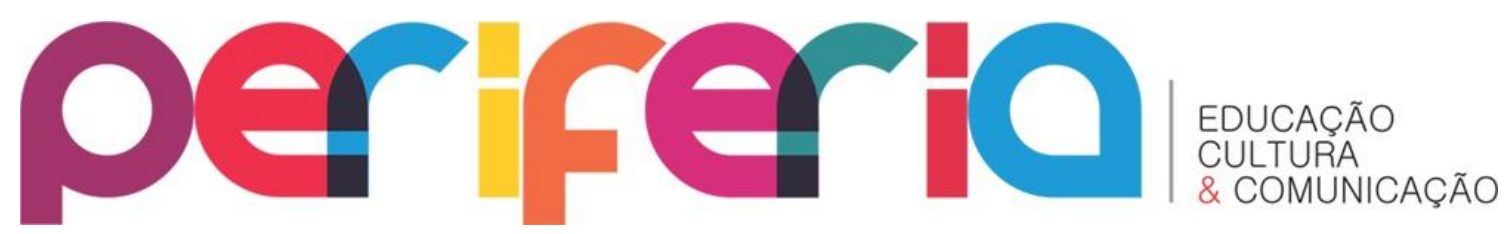

Utilizamos também os estudos de Joan Scott, que faz uma relação entre o conceito de gênero e experiência, a partir do diálogo, com os historiadores da cultura, entre eles E. P. Thompson:

No uso que Thompson faz do termo, experiência é o início de um processo que culmina na percepção e articulação da consciência social, nesse caso, de uma identidade comum de classe. Tem uma função integradora, unindo o individual e o estrutural e pessoas diversas num todo coerente (totalizador) que é um senso distinto de classe (SCOTT, 1999, p. 34).

As duas citações anteriores são importantes para compreendermos o conceito de gênero, forjado a partir das relações sociais. As autoras citadas anteriormente apontam em uma direção na qual o gênero é produto das relações sociais e não de condicionamentos biológicos. Essas relações sociais constroem a identidade dos indivíduos, articulada ao conceito de classe. As meninas desvalidas do Educandário Nossa Senhora da Piedade, ao mesmo tempo são identificadas por sua pobreza e pelo gênero. A palavra desvalida era usada pelo Estado Imperial, para indicar os indivíduos, sem vencimentos que pudessem sustentar sua prole. Para educá-las, a condessa do Rio Novo acionou outro grupo social: a Igreja. Através das irmandades religiosas, que administrava tanto escolas para ricos como para pobres, transmitia seus dogmas e visões de mundo.

\section{UMA ANÁLISE DO CURRÍCULO DAS MENINAS DESVALIDAS DO EDUCANDÁRIO NOSSA SENHORA DA PIEDADE, $1925-1930$}

Moreira e Tadeu (2013) denunciam que, o currículo representa um artefato social e cultural, deixando de representar uma área da didática, voltada apenas, para as questões técnicas, o currículo expressa relações de poder.

O currículo há muito tempo deixou de ser apenas uma área meramente técnica, voltada para questões relativas a procedimentos, técnicas, métodos. (...) 0 currículo é considerado um artefato social e cultural. Isso significa que ele é colocado na moldura mais ampla de suas determinações sociais, de sua história, de sua produção contextual. O currículo não é um elemento inocente e neutro de transmissão 


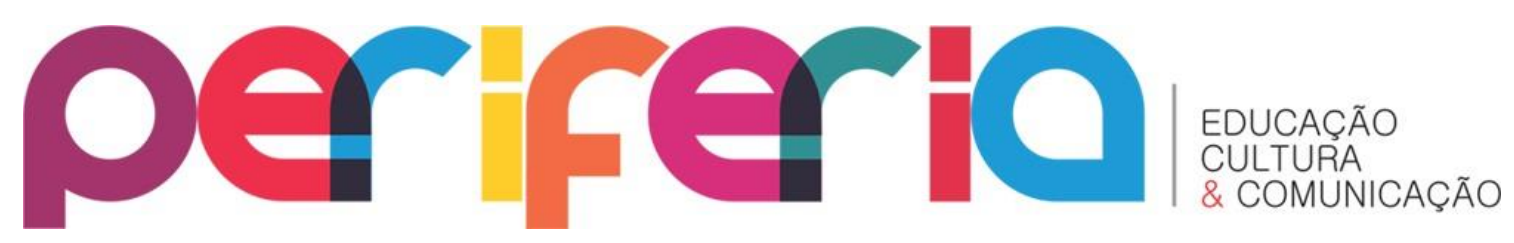

desinteressada do conhecimento social (MOREIRA e TADEU, 2013, p. 7-8).

Zotti (2004) contribui para nosso trabalho, ao fazer reflexões sobre o currículo na Primeira República. De acordo com esta autora, havia uma distinção entre as escolas destinadas ao povo e as escolas destinadas aos filhos da elite, devido à necessidade de formar o trabalhador livre e atender o interesse das elites agrárias, que comandavam o país. A escola era uma das instâncias, onde era travada uma luta ideológica que se expressava no currículo e estava impregnada pela visão de mundo da elite. O grupo dominante na República, para manter as relações de poder, desobrigou o aparelho estatal de investir no ensino primário, destinando mais recursos para o ensino secundário e superior, onde estavam os filhos da elite.

Para os defensores dessa sociedade, a educação continuava sendo um artigo de luxo restrito às classes favorecidas, sendo privilegiado, portanto, o ensino secundário e superior em detrimento da expansão do ensino primário. Essa realidade foi consagrada legalmente com a Constituição de 1891, que reafirmou a descentralização escolar. Já definida em 1834, cabendo agora aos estados a responsabilidade de manter e legislar sobre o ensino primário e o ensino profissional (ZOTTI, 2004, p. 67-68).

A autora caracteriza a década de 1920, como um período fértil em discussões pedagógicas, a educação era colocada como, uma mola propulsora do desenvolvimento econômico. 0 ensino primário na década de 1920, estava restrito ao ensino das primeiras letras e não era obrigatório. Não havia um sistema de ensino que integrasse os diferentes níveis de ensino.

A década de 1920 marcou a educação brasileira mais pela discussão do que propriamente pelos resultados concretos. Os educadores, reunidos em movimentos conhecidos como entusiasmo pela educação e otimismo pedagógico, propunham a instituição de um sistema nacional de educação, num todo articulado do primário, já que a educação era vista como a grande responsável pelo progresso do país. (...) Das diversas reformas ocorridas durante esse período, a Reforma Benjamim Constant, em 1890 , foi a única que atingiu o ensino primário, buscando complexificar o conjunto de disciplinas curriculares, porém restrito ao Distrito Federal. Apesar dessa tentativa, o 


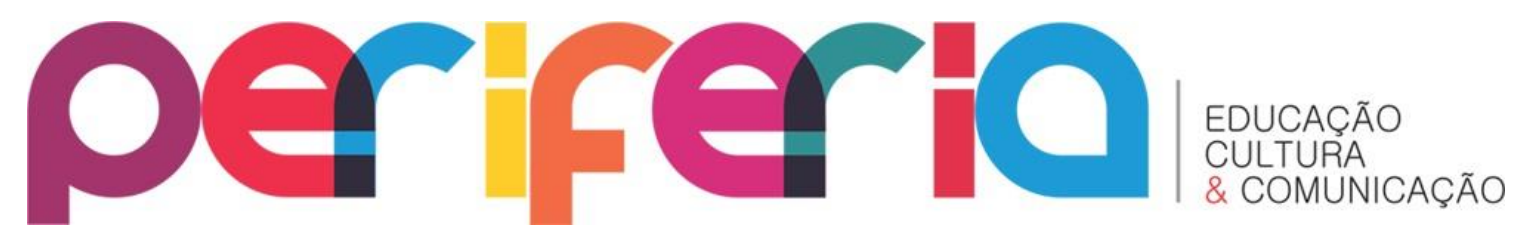

ensino primário brasileiro ficaria restrito até 1920 ao ensino das primeiras letras, ou seja, o aprendizado da leitura, da escrita e do cálculo, definido no decreto imperial de 1827 . Somente com as reformas estaduais é que se inicia um processo de discussão de propostas para o ensino primário (ZOTTI, 2004, p. 70-1).

As instituições religiosas também possuíam o seu currículo. Madeira (2008), apresenta um rico quadro, que nos permite comparar os currículos e os objetivos das instituiçõos e de seus agentes formadores.

Em geral, sua atenção voltava-se particularmente para a construção de abrigos que se propusessem a educar, sustentar e casar as órfãs desamparadas, acolher crianças rejeitadas, amparar e ocupar mulheres consideradas perdidas. As Casas deveriam, portanto, tornar-se um lugar de formação feminina, com base na moral cristã e no trabalho, com vistas à purificação do corpo e, conseqüentemente, da alma. Com esse intuito, elas eram confinadas aos limites das Casas, sob as vistas de "irmãs superiores" e "irmãs mestras", para evitar o contato com o mundo, entendido como espaço da ociosidade e de extravio do espírito (MADEIRA, 2008, p. 27-28).

A citação acima apresenta o ideal de educar e regenerar as mulheres “perdidas" cabendo as religiosas diminuir o contato com o mundo, pois o mesmo era a raiz do ócio e das paixões mundanas. Utilizando como fontes documentais as cartas trocadas por Ibiapina e as religiosas, periódicos locais, Madeira (2008) reconhece não saber o número total de meninas e mulheres “perdidas", devido às perdas documentais sofridas pelos acervos pesquisados. 0 principal meio de comunicação entre o padre e as religiosas eram as cartas. Por meio delas, tomava conhecimento do trabalho realizado nas vinte e duas casas de caridade, fundadas em quatro estados do Nordeste.

Contudo, as cartas revelam o ponto de vista do padre, das irmãs, mas não são documentos nos quais as mulheres "perdidas" ou as meninas falavam de si, de seu mundo e de seus sonhos, deste modo. Dessa forma, ela se constitui no discurso de um homem sobre as mulheres e meninas desvalidas, ou o discurso de mulheres que abraçaram a vida religiosa. Isso nos permite inferir que não conheceremos o que as mesmas pensavam sobre a educação que recebiam. 


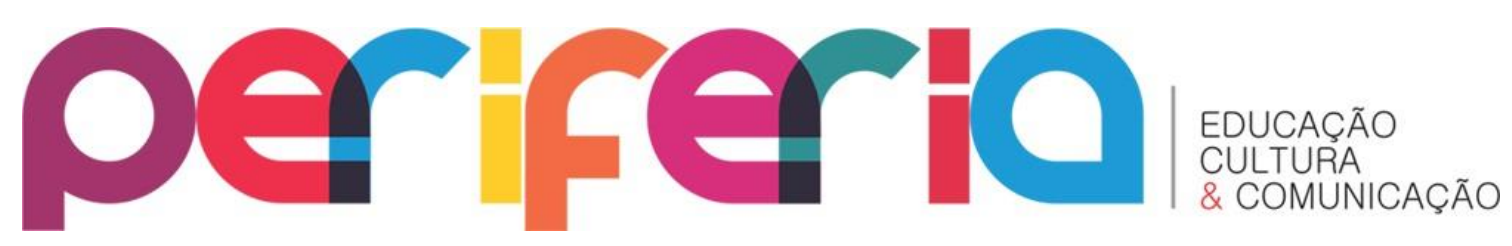

O sustento dessas casas era feito através de doações e do método da subscrição, diferente do Educandário Nossa Senhora da Piedade, que possuía renda própria, deixada pela Condessa do Rio Novo. Em seu testamento a Condessa determinava: deixo a Casa de Caridade de Paraíba do Sul, cem apólices da Dívida Pública no valor nominal de um conto de réis cada uma, as quais serão inalienáveis e constituirão perpetuamente o patrimônio daquele Pio estabelecimento, que só poderá despender os juros.

Outra pergunta surge da leitura do livro de Madeira (2008), como eles poderiam educar as meninas desvalidas junto com as mulheres consideradas de má reputação? Havia espaços separados? Da convivência entre elas, as mulheres presentes na casa, através de conversas, poderiam "educar" as meninas, sem que as religiosas percebessem? As mulheres consideradas "perdidas", e as meninas desvalidas não possuíam demandas diferentes?

O currículo dessa instituição baseava-se na moral cristã e no trabalho, com o objetivo de purificar o corpo e a alma. Nessa instituição, era travado um grande combate contra a ociosidade, contra o riso e contra as conversas em demasia. 0 padre Ibiapina e as irmãs de caridade, escreveram longas cartas, recomendando a severidade dos hábitos, o combate ao luxo, pois este era considerado pecaminoso e desnecessário às mulheres honestas, que desejam levar uma vida simples e decente.

No que se refere ao refinamento dos modos, aconselhava a todas que fossem fiéis, pontuais, falassem baixo e com poucas palavras; não abrissem ou fechassem portas com ruídos, pois era tido como sinal de má educação; que as beatas não fossem curiosas e evitassem familiaridades e amizades particulares com as meninas; que estas não fizessem sozinhas aquilo que não se animariam a fazer diante das superioras (MADEIRA, 2008, p.100).

A Igreja Católica possuía uma base comum, para educar a todas as mulheres. Eram considerados hábitos grosseiros, como falar alto e em demasia. Os mecanismos de vigia deveriam ser internalizados pelas meninas, pois recomendava-se que não praticassem atos, que fugissem aos ensinamentos. Eles desaconselhavam o segredo. Essas prescrições também revelam a 


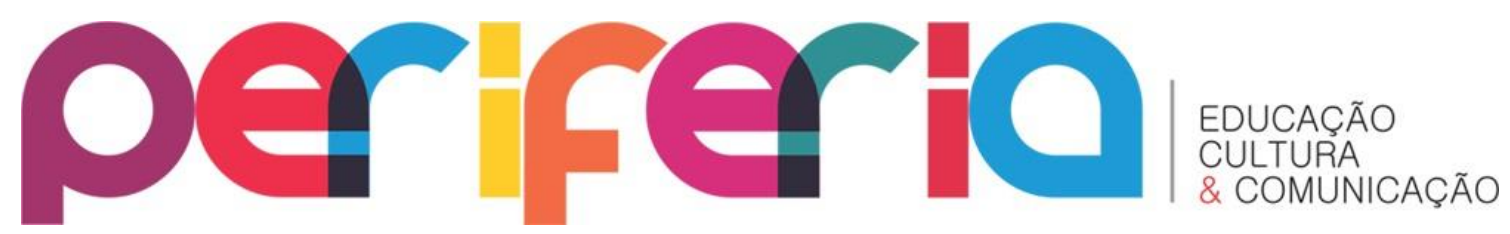

dominação masculina sobre o mundo feminino, delas, nem mesmo as religiosas escapavam. As atividades começavam muito cedo, na verdade ainda de madrugada.

[...] As congregadas levantavam-se às 4 horas [...] as meninas às 5 horas da manhã [...]. Além da preocupação com hábitos higiênicos, com o de "nas quintas-feiras em logar de tocar a campa para as escolas, as Mestras ocupam-se em limpar as meninas, cortando unhas, cabellos, mandando tomar banho" recomendava ainda toalhas cheirosas nas capelas (MADEIRA, 2008, p.100).

O cuidado com o corpo e com a Alma estavam presentes nas recomendações do padre Ibiapina. Os hábitos de higiene deveriam ser estimulados. Dessa forma, recomendava-se levantar cedo. Um dispositivo sonoro era usado para ordenar as atividades. Era responsabilidade das irmãs de caridade dar banho, cortar unhas e cabelos das meninas em dias determinados. Elas deveriam cuidar da alma, expresso no cuidado com as toalhas cheirosas presentes na capela. No Educandário Nossa Senhora da Piedade, as atividades também começavam cedo. As asiladas deveriam levantar-se às 5 horas da manhã.

As asiladas levantaram-se no verão às 5 horas da manhã e durante o inverno às 6 horas, deitando-se às 8 horas da noite. Consagram 5 horas ao estudo e outras tantas ao trabalho manual, entrecortadas pelas refeições e recreios gastando nestes não menos de 3 horas (RELATÓRIO DO PROVEDOR, 1925, p. 9).

O documento não faz menção ao horário que as religiosas se levantavam, deveria ser antes das meninas, para que as mesmas pudessem dirigir as preces matutinas. Hilsdorf (2005), em seu texto intitulado "Tão longe, tão perto: as meninas do seminário" fornece-nos subsídios, que nos possibilita compreender as propostas educacionais para as meninas desvalidas. 0 objetivo da autora é conhecer o Seminário das educandas, desligado da Roda dos Expostos, adotando como hipótese que o seminário possuía proposta educativa.

0 alvo da instituição eram as meninas órfãs de militares, cujas famílias estavam sem proventos. As meninas tinham entre oito e treze anos de idade, Periferia, v. 10, n. 2, p.158-180, jul./dez. 2018 


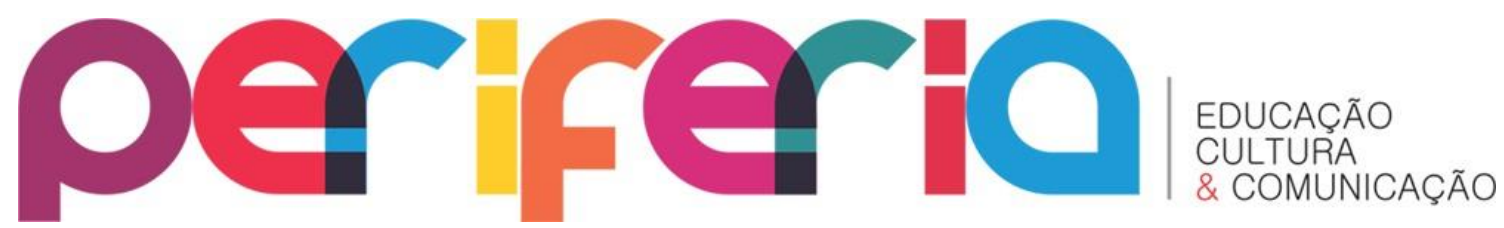

aceitando também pensionistas. Hilsdorf citando Marcílio nos diz que, a Santa Casa de Misericórdia e a Roda dos Expostos, não possuíam propostas educacionais sistematizadas, o que orientava a ação dessas instituições, era o desejo de tirar as crianças do ócio e direcioná-las ao mercado de trabalho.

O Seminário das Educandas pode ter tido como inspiração próxima a obra de Napoleão Bonaparte, que segundo R. Rogers (1993, p.-43-51), ao reorganizar os serviços educacionais franceses no período pós-revolucionário, negligenciou a educação feminina pública, mas criou as "Escolas da Legião da Honra" para as filhas dos seus oficiais perecidos em batalhas, com o objetivo de dar-lhes formação moral para serem boas esposas e mães de família. O Seminário também antecipou em dois anos as escolas elementares públicas para mulheres (1827), e como aquelas escolas francesas, também tinha em vista as órfãs dos militares mortos nas guerras da Independência (HILSDORF, 2005, p.60-61).

A citação anterior, nos mostra que, o objetivo das escolas femininas, era a formação moral das mulheres, preparando-as para ser boas esposas e mães, esse ideário estava presente no Brasil colônia em diferentes regiões, como nos mostra Algranti analisando a Santa Casa de Misericórdia de Pernambuco:

Os estatutos da Santa Casa advertem: no tempo que thes sobejar desses exercícios espirituais, se ocuparão em coser, fazer rendas e aprender todas as mais coisas que são necessárias a uma mulher honesta e a uma boa mãe de família para que com suas prendas adquiridas facilitem melhor o seu estado (ALGRANTI, 1993, p.103).

Atravessando o tempo, da Colônia a República guardando as devidas especificidades regionais, percebemos que a formação de mulheres para ser boas mães e esposas, também estava presente no Educandário Nossa Senhora da Piedade em Paraíba do Sul. Essas práticas baseavam-se na moral cristã, que possui sua base teórica nas Escrituras Sagradas e na tradição.

Aprendam a lavar, engomar, cosinhar, exercitam-se em todos os trabalhos domésticos próprios de uma boa mãi de família. Tanto nos estudos como nos trabalhos manuaes as asyladas 


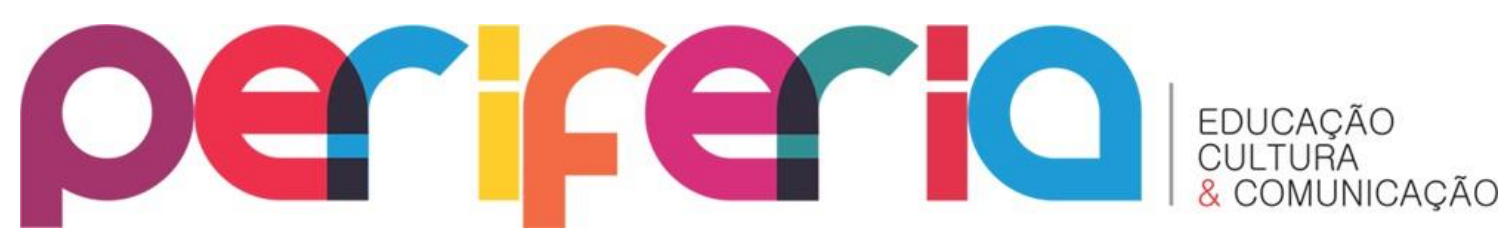

estão sempre sob a vigilância de uma das Irmãs de Caridade (RELATÓRIO DO PROVEDOR, 1925, p.11).

O projeto educativo Católico apresentava nuances, que não podemos perder de vista. As escolas destinadas a formar a fina flor da elite fluminense, que estudavam nos colégios confessionais, não eram regidas pelas mesmas regras que as meninas pobres. Numa rápida mirada nos currículos desses colégios encontramos aulas de Latim, Francês entre outras disciplinas.

Alessandra Schueler ao analisar o processo de construção das escolas no Império, destaca a atuação de Antônio Ferreira Viana, que empreendeu um grande esforço, para a construção de escolas, entre elas o Instituto Ferreira Viana, construído na antiga Casa de São José, na Rua General Canabarro, no bairro da Tijuca, no Rio de Janeiro. No momento, nos são relevantes às reflexões da autora sobre o currículo proposto para as escolas públicas do Rio de Janeiro, sobretudo, aquelas destinadas a atender os desvalidos.

A historiadora destaca que os currículos dessas escolas eram formados por rudimentos da geografia e história pátria, a música e o desenho linear. Havia um currículo diferenciado para as meninas, que também eram separadas dos meninos nos exercícios de ginástica. Vejamos o currículo proposto para a formação dos meninos:

Pelo currículo das escolas municipais, elaborado pelo diretor e professor da escola de meninos. Candido Matheus de Faria Pardal, as matérias ensinadas compreendiam: instrução religiosa, leitura e escrita, aritmética, sistema métrico, desenho linear e noções de gramática. As turmas deveriam ser divididas em oito classes de ensino, conforme o adiantamento dos alunos, tendo o curso primário duração regular de quatro anos, estendendo-se mais ou menos conforme o andamento das classes (SCHUELER, 2001, p.172).

Para as meninas eram ensinadas as mesmas matérias com o acréscimo de conteúdos, que visavam formar as mães de família.

As meninas aprendiam as mesmas matérias que os meninos, acrescentando-se, porém, os trabalhos de agulha e costura, considerados necessários à educação das "futuras mães de 


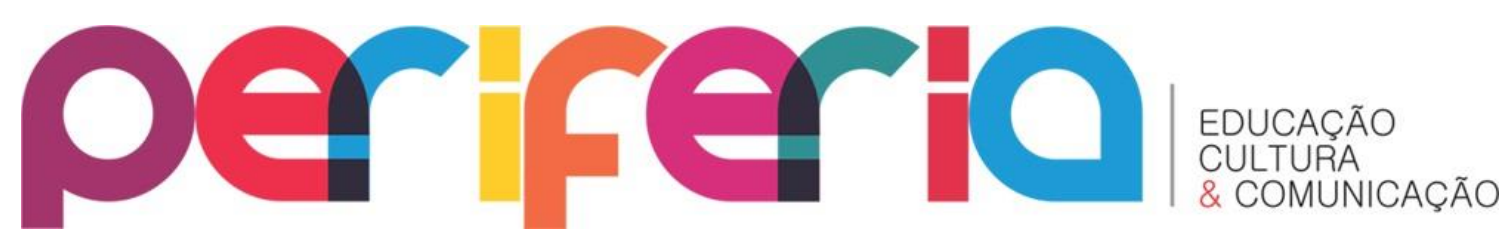

família" tal qual o programa de instrução primária definido pelo Regulamento de 1854 (SCHUELER, 2001, p.172).

Nossos argumentos ganham força com a citação feita anteriormente, ao apresentar o Regulamento de 1854 ressaltando a necessidade de incluir na da formação das meninas, conteúdos que visavam a formação da mulher para o lar. As meninas desvalidas do Educandário Nossa Senhora da Piedade em Paraíba do Sul seguiam um rígido código de disciplina, que estabelecia o tipo de punição que deveria ser aplicado. Há um documento que explica o que pode provocar a expulsão de uma menina da instituição:

Art. $5^{\circ}$ - A educanda que por seu máo procedimento e depois de esgotados todos os meios brandos, merecer ser expulsa, será pela Mesa posta à disposição de seu pai ou tutor ou Juiz de Orphãos, quando não tenha pai ou tutor, e dada a recusa deste, a Mesa lhe dará conveniente destino.

Parágrafo $1^{\circ}$ - Sem the ser, apresentado por escripto, licença especial do Provedor, a Irmã Superiora não consentirá que qualquer asylada saia para pernoitar fora do estabelecimento. A que infringir a disposição deste parágrapho não será mais recebida e seu lugar será considerado vago (RELATÓRIO DO PROVEDOR, 1926, p.13).

A saída das meninas da instituição sem o consentimento do Provedor e da Irmã Superiora à noite, se prolongando até o outro dia, era um fato que permitia a expulsão da menina, do Educandário, pois temia-se a prostituição. Onde ela teria passado à noite? O texto não fala explicitamente, porém deixa escapar que algumas meninas fugiram e suas vagas foram colocadas a disposição da Mesa administrativa para serem preenchidas por outras meninas, que deveriam observar o código de conduta de uma instituição católica de ensino feminino.

O código disciplinar do Educandário Nossa Senhora da Piedade punia com o jubilamento a menina que pernoitasse fora do estabelecimento sem autorização do Provedor e da Irmã Superiora. Com relação a idade, encontramos alunas com idades diversas, no Educandário Nossa Senhora da Piedade, inclusive localizamos seis menores com menos de seis anos, “admitidas no asilo por espírito de Humanidade e Caridade, por serem mui necessitadas". 


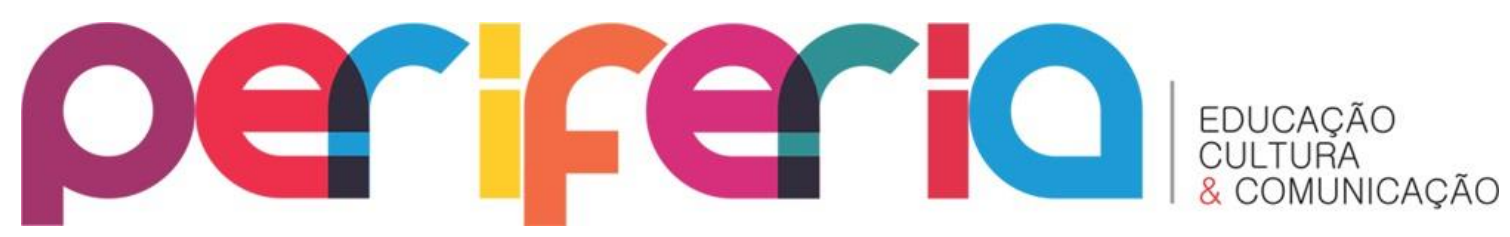

Consideramos as contribuições de Gondra e Schueler positivas ao pontuar a existência de asilos privados, asilos religiosos, asilos para a educação da elite, asilo para a educação de meninos e de meninas desvalidas demonstrando assim, que públicos distintos valiam-se de estratégias semelhantes para educar seus rebentos. Esses e outros autores reconhecem a importância das estratégias criadas para dar assistência às crianças abandonadas na Colônia, no Império e na República. Os mesmos autores, apontam também a separação das idades e a atuação das freiras na educação de crianças pequenas.

As crianças pequenas necessitavam de numerosas recreações, estudos muito curtos, alimentação equilibrada, apropriada e de uma vigilância feita por um pessoal devotado que, em sua prescrição, deveria ser feita por freiras, habituadas a esse serviço e que a ele se dedicavam de modo geralmente admirável (GONDRA; SCHUELER, 2008, p.111).

Outro estudo, que também apresenta a participação das freiras na educação, é o texto de Maria José Rosado Nunes, no qual a autora destaca que as freiras foram às primeiras mulheres a exercer uma profissão. Com a criação das irmandades para mulheres, no século XIX, as associações femininas de piedade, também foi criada em paralelo uma rede de escolas, dirigida por freiras estrangeiras, tendo como público alvo a educação de meninas.

As mulheres se beneficiaram de algumas iniciativas católicas dessa época, sobretudo da educação, mas também com a criação das associações femininas de piedade. Dessas iniciativas, a mais carregada de efeito para as mulheres foi a criação de uma rede de escolas católicas, sob a direção de religiosas estrangeiras. O século XIX presenciou ainda um desenvolvimento bastante rápido das "escolas para meninas", que tiveram as religiosas como elementos fundamentais (NUNES, 2007, p. 491).

$\mathrm{Na}$ esteira desses dois textos citados anteriormente, incluímos o nosso objeto de pesquisa, que analisa uma instituição religiosa dirigida pelas Irmãs Vicentinas, destinadas às meninas desvalidas. 0 Educandário Nossa Senhora da 


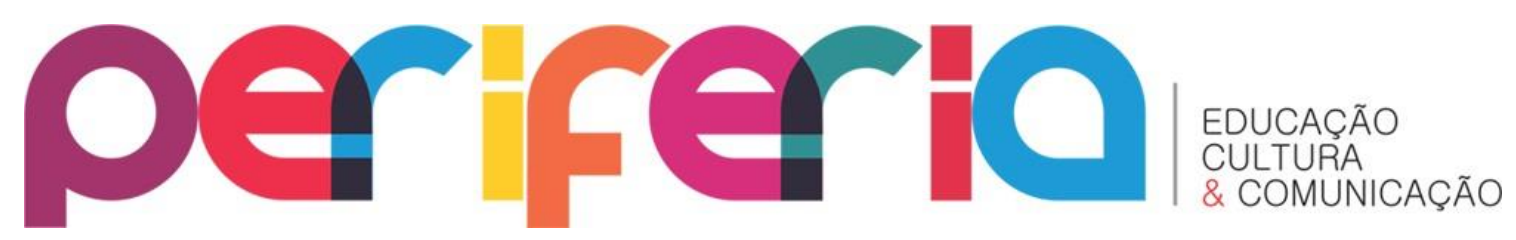

Piedade, foi e continua sendo dirigido, pela Irmandade Nossa Senhora da Piedade, fundada em Paraíba do Sul, pela condessa do Rio Novo.

Gondra e Schueler (2008), ao sistematizar a evolução da malha educacional destinada a atender as crianças desvalidas, traçaram um quadro composto pelo Asilo dos Inválidos da Pátria, o Asilo da Mendicidade da Corte, a Associação Protetora da Infância Desvalida, e outras instituições do gênero criadas na província do Amazonas, citando as pesquisas de Rizzini.

Os mesmos fazem menção da Escola Doméstica Nossa Senhora do Amparo em Petrópolis, a Casa de Caridade, em Vassouras e o Asilo Santa Isabel. Todas essas instituições citadas foram criadas no mesmo período, o que nos permite dizer como o Estado direcionou o projeto educacional, na segunda metade do XIX, sem esquecer dos pobres.

No que se refere aos Institutos profissionais, os trabalhos de Rizzini (2001 e 2004) traçam um quadro importante, demonstrando a ramificação desse tipo de iniciativa no Brasil e a perspectiva assumida, como se pode ver no levantamento, que, aliás, deve ser precisado com o desenvolvimento de mais estudos em cada uma das províncias (GONDRA; SCHUELER, 2008, p. 121).

O Educandário Nossa Senhora da Piedade, entra na brecha deixada por Gondra e Schueler, pois é uma instituição criada, no interior do estado do Rio de Janeiro em 1882, ou seja, contemporânea das instituições analisadas por eles. $O$ estudo dessa instituição contribuirá na composição do quadro maior, que ainda carece de estudos, que é a história das instituições escolares no estado do Rio de Janeiro, as quais ainda se encontram a sombra, da história econômica e política, ou dispersas, necessitando de uma análise mais consistente.

\section{CONSIDERAÇÕES FINAIS}

Em nosso texto procuramos analisar os contornos da educação feminina, além dos muros do Município da Corte (hoje Município do Rio de Janeiro). 


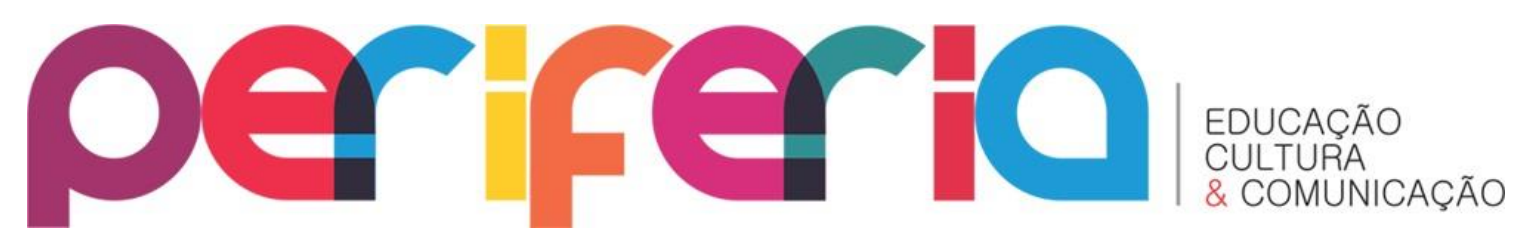

Visitamos o Educandário Nossa Senhora da Piedade, que foi fundado no ano de 1884. Fizemos um esforço para apresentá-lo sem perder de vista o contexto histórico no qual foi criado. Apresentamos o prédio e sua belíssima estrutura, fazendo correlação com a sua proposta pedagógica. Sem esquecer da sua importância como local de abrigo e educação na região, destacando a visita do Conde D`Eu, esposa da princesa Isabel, que em visita a cidade vizinha de Vassouras passou por Paraíba do Sul para conhecer o andamento das obras que visavam a expansão da Instrução Pública, feita em parceria com os homens e mulheres da nobreza.

Concordamos com Antônio Flávio e Tomas Tadeu, que constroem o conceito de currículo como um artefato histórico, político, social e cultural. 0 estudo das questões de gênero atravessando o currículo do Educandário Nossa Senhora da Piedade, nos permitiram conhecer o projeto educativo da Igreja para as meninas pobres, dialogar com outras instituições de educação feminina, tais como as criadas pelo padre Ibiapina mantida também pelas irmãs de caridade no Nordeste. A aliança entre a Igreja e o Estado se fez presença para forjar e manter um projeto de sociedade, e também, os grupos dominantes no poder. A educação era (e, ainda, é) uma arena de disputa, na qual os seus representantes buscaram/buscam espaço para os seus projetos. Preparadas para serem boas mães, essas meninas poderiam reescrever suas histórias. A educação que as meninas recebiam, também estava recoberta pela capa da disseminação da fé cristã, dos bons hábitos, e nossa reflexão lança luzes sobre dominação masculina, no período.

\section{REFERÊNCIAS}

ALGRANTI, Leila Mezan. Honradas e devotas: mulheres da colônia. Rio de Janeiro: José Olympio, 1993.

FOUCAULT, Michel. Vigiar e Punir: História da Violência nas prisões. Petrópolis, RJ: Vozes, 1987.

FLEXOR, Maria Helena Ochi. Inventários e testamentos como fontes de pesquisa. In: CASIMIRO, Ana Palmira B. S.; LOMBARDI, José Claudinei; MAGALHÃES, Lívia 


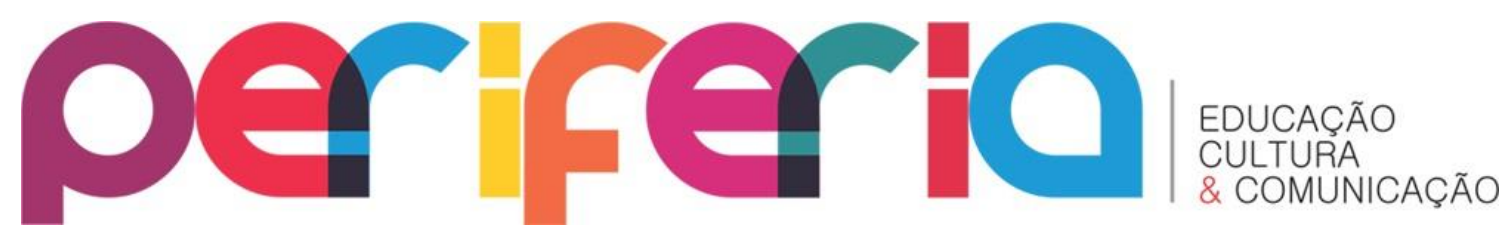

Diana R. (Orgs). A pesquisa e preservação de arquivos e fontes para educação, cultura e memória. Campinas, SP: Editoria Alínea, 2009.

GONDRA, José Gonçalves e SCHUELER, Alessandra. Educação, poder e sociedade no império brasileiro. São Paulo, SP: Cortez, 2008.

HILSDORF, Maria Lúcia Spedo. Tão longe, tão perto: as meninas do seminário. In: BASTOS, Maria Helena Câmara e STEPHANOU, Maria. (Org.). História e memória da educação no Brasil. Vol. II: Século XIX. Petrópolis, RJ: Vozes, 2005.

MADEIRA, Maria das Graças de Loiola. A pedagogia das casas de caridade do padre Ibiapina. Fortaleza, CE: Edições UFC, 2008.

MOREIRA, Antônio Flávio e TADEU, Thomas (Orgs.). Currículo, Cultura e Sociedade. São Paulo: Cortez, 2013.

NUNES, Maria José Rosado. Freiras no Brasil. In: DEL PRIORE, Mary (org). História das Mulheres no Brasil. 9. ed. São Paulo: Contexto, 2007.

PENNA JUNIOR, Randolpho. Relatório de Compromisso da Irmandade Nossa Senhora da Piedade de Paraíba do Sul. Paraíba do Sul: Irmandade Nossa Senhora da Piedade, 1930.

RIBEIRO NETO, Alexandre. Tenha Piedade de nós: uma análise da educação feminina do Educandário Nossa Senhora da Piedade em Paraíba do Sul, 19251930. Dissertação em Educação. UNIRIO - Universidade Federal do Estado do Rio de Janeiro, 2010.

SCHUELLER, Alessandra F. Martinez de. A Associação Protetora da Infância Desvalida e as Escolas de São Sebastião e São José. In: MONARCHA, Carlos (org.) Educação da infância brasileira, 1875-1983. São Paulo: SP, Autores Associados, 2001.

ZOTTI, Solange Aparecida. Sociedade, Educação e Currículo no Brasil: dos jesuítas aos anos de 1980. Campinas, SP: Autores Associados; Brasília, DF: Editora Plano, 2004. 